\title{
Habitação e saúde
}

\section{SUZANA PASTERNAK ${ }^{I}$}

\section{Introdução}

$\mathrm{O}$ CONCEITO de habitação já é bastante impreciso. Que características teriam em comum um chalé suíço, um iglu ou um apartamento num arranha-céu em zona urbana? E é indiscutível que são locais de moradia. Quando se fala em habitação, leva-se em conta não só a unidade habitacional, mas também os aspectos de integração dessa unidade na trama urbana, além do grau de atendimento a serviços de infraestrutura e equipamento social. Assim, o conceito de habitação adequada envolve pelo menos esses dois níveis. Relatório da WHO (2010) inclui quatro aspectos na definição de habitação:

- casa (house)- ou seja, a estrutura física;

- lar (bome)- a estrutura econômica, social e cultural estabelecida pela família (household, grupo doméstico) residente;

- bairro (neighbourhood) - são ruas, lojas, igrejas, escolas, área verde e de recreação, transporte etc., que circundam a casa;

- Comunidade - inclui os que moram, trabalham ou prestam serviços no bairro.

Habitação e meio ambiente têm profundo impacto na saúde humana: é estimado que se passem $80 \%$ a $90 \%$ do dia em meio ambiente construído e a maioria desse tempo em casa. Assim, riscos em relação à saúde nesse ambiente são de extrema relevância. O papel da habitação para a saúde é ainda realçado porque são justamente os mais vulneráveis (doentes, idosos, crianças, inválidos) que lá passam a maior parte do seu tempo.

Mas qual o significado do termo habitação adequada, e como mensurá-la?

Uma moradia edificada em 1950 e comportando somente adução de água e gás poderia passar perfeitamente por decente na França da época. Hoje, a ausência de sanitários nos apartamentos nos parece escandalosa. Exige-se sala de banhos, aquecimento central, isolamento acústico, garagem. Existe a tendência a considerar todas essas comodidades como um mínimo. Muitos vão demandar lugar para guardar seu carrinho de nenê, suas bicicletas e ferramentas. Outros reclamarão mais terraços, água quente no imóvel, uma cozinha funcional, tubo de lixo, lavanderias coletivas, antenas para rádio e televisão, telefone. Em compensação, não se tem mais cocheiras, escadas separadas para fornecedores, quartos de empregadas no sótão. (Havel, 1968, p.11)

A citação de Havel data dos fins da década de 1960. Atualmente a TV a cabo e a internet introduzem novas necessidades. Mas o que se percebe é que o conceito é histórico e regional. Em regiões frias, o aquecimento central é ne- 
cessidade, o que não acontece em Belém do Pará, por exemplo, onde mesmo o chuveiro elétrico poderia ser dispensado.

As intervenções na legislação da habitação mínima ligam-se, no seu início, à legislação de saúde pública inglesa, de 1848. Essa lei permitia a intervenção estatal no tecido urbano quando solicitado por uma décima parte dos habitantes de um núcleo urbano, ou quando seu coeficiente de mortalidade nos últimos sete anos tivesse sido superiro a 23/1000. Obrigava, entre outros itens, toda casa a ter um sanitário e eliminação de dejetos apropriada, normatizava casas de aluguel, proibindo o aluguel de porões e determinando requisitos de limpeza e ventilação, abastecimento de água e pavimentação dos caminhos. Na França, embates entre socialistas e católicos polemizaram as intervenções na moradia, até que uma epidemia de cólera em 1849 foi motivo determinante para aprovação de lei em abril de 1850, permitindo intervenção e inclusive desapropriação de unidades habitacionais consideradas insalubres. Nos Estados Unidos, em 1939, o Commitee on the Hygiene of Housing publica, pela primeira vez, os Basic principles of healthful housing. Esse relatório divide-se em quatro sessões e coloca trinta princípios, ligados às necessidades fisiológicas (temperatura, ar, luz solar, iluminação artificial, proteção contra barulho, espaço para brincar), necessidades psicológicas (privacidade, desenvolvimento de vida familiar e comunitária), equipamentos domésticos para minimizar fadiga física e mental, facilidade de limpeza e manutenção, satisfação estética, concordância com standard social vigente, proteção contra contágio (água, esgoto, lixo, proteção contra vetores, espaço nos dormitórios para minimizar contágio de doenças), proteção contra acidentes (matérias de construção, choques, fogo, gás, cuidados projetuais para minimização de acidentes). Baseada nessas recomendações, a American Public Health Association (APHA, 1945) chegou até a patrocinar uma escala numérica de adequação residencial.

O movimento sanitarista exerceu forte influência nas políticas de saúde pública até o fim do século XIX, por meio de legislações e obras de engenharia. No século XX, entretanto, esse movimento perdeu força com o início da era bacteriológica e a ênfase maior dada à prevenção pessoal (vacinação). Segundo Westphal (2000) a retomada da ideologia sanitarista aconteceu apenas na década de 1970, quando a medicina curativa, por seus altos custos tecnológicos, entrou em crise. Essa "nova saúde pública" sugere que a medicina sozinha não pode resolver os problemas de saúde, necessitando se articular com outros campos do conhecimento, como urbanismo, habitação, meio ambiente, cultura, transporte, educação, lazer.

A Organização Mundial da Saúde (OMS), após a publicação do Informe Lalonde no Canadá em 1974 (Hermeto, 2009, p.150), “deu início a uma série de conferências internacionais de forma a divulgar o novo conceito de promoção da saúde". Essas conferências culminaram com a I Conferência Internacional sobre Saúde, em Ottawa, no Canadá, em 1986, que enfatizou a interseto- 
rialidade implicada: "O conceito saúde, como bem-estar, transcende o setor saúde”. E completa: “as condições e requisitos para a saúde são: paz, educação, alimentação, ecossistema estável, recursos sustentáveis, justiça social e equidade” (Buss apud Hermeto, 2009, p.150). Um ano mais tarde, a OMS estabeleceu uma comissão com o objetivo de delinear uma política de habitação saudável, lançando um documento Housing-implications for health (WHO, 1987). Influenciada por essas recomendações, a Organização Pan-americana de Saúde em 1995 implementou a criação da Red Interamericana de la Vivienda Saludable, que originou, em 2000, a Rede Brasileira de Habitação Saudável (RBHS) (Cohen et al., 2007).

No Brasil, o conceito de déficit habitacional acaba por dimensionar, indiretamente, o que se chama, hoje, de habitação adequada. A Fundação João Pinheiro (2008, p.11), responsável por esse cálculo, coloca alguns pressupostos: o primeiro fala "que numa sociedade profundamente hierarquizada e desigual como a brasileira, não se deve padronizar as necessidades de moradia para todos os estratos de renda". Isso justificaria a adoção de paramentos distintos para locais e camadas de renda diferentes. A aceitação desse pressuposto visa permitir incluir no estoque aceitável parte das moradias em favelas, justificando inclusive sua urbanização e aceitação, dentro de marco legal, de unidades que seriam interditadas no chamando mercado formal. O segundo pressuposto, que reforça o já exposto, é "que a discussão do tema habitacional possui fortes interfaces com outras questões recorrentes e complementares” (ibidem, p.13). A relação da política habitacional com outras políticas urbanas é um aspecto importante a ser considerado e nem sempre um simples incremento nos programas de habitação seria solução mais adequada para melhoria das condições de moradia das populações pobres. Introduz, assim, o conceito de inadequação dos domicílios, partindo do pressuposto de que em muito casos a melhor forma de enfrentar o problema habitacional seria implementar políticas complementares e não, obrigatoriamente, construir mais unidades de moradia. Dessa forma coloca como indicadores de moradia inadequada dois grupos: um, referindo-se a unidades totalmente inadequadas, com substituição obrigatória; outro, onde as unidades seriam no momento inadequadas, mas passíveis de reforma ou colocação de algum equipamento para se enquadrarem na norma vigente. As unidades habitacionais totalmente inadequadas seriam os domicílios improvisados (por exemplo, grutas, carros, tocas, barracas) e rústicos (construídos com materiais que não alvenaria ou madeira aparelhada) e com adensamento excessivo em moradias alugadas (o indicador utilizado refere-se a unidades habitacionais de aluguel onde, nos cômodos utilizados para dormir, existam mais de três pessoas). A esses dois aspectos materiais se somam outros dois relativos à forma de ocupação: unidades com ônus excessivo de aluguel (mais de 30\% da renda familiar) e casas onde existe coabitação familiar involuntária). Em relação aos aspectos materiais, o conceito de domicílio improvisado ou rústico obtém unanimidade. Sobre famílias conviventes, o conceito já foi modificado, dado que o anterior coloca 
como déficit, e portanto moradia inadequada, toda a unidade com mais de uma família, refletindo o ditado popular "quem casa quer casa". Questão introduzida pela PNAD 2007 permitiu observar que esse axioma nem sempre era verdadeiro, e a coabitação familiar era, inúmeras vezes, voluntária, como parte de estratégia de sobrevivência. E, em relação ao ônus excessivo com aluguel urbano, a discussão tem sido que o mais adequado seria subsidiar o aluguel, não havendo necessidade de construir mais unidades. Nota-se também que o indicador utilizado para adensamento excessivo, de três pessoas por dormitório, tem alto grau de voluntarismo: por que três e não duas, como utilizado em outros países? $\mathrm{E}$ também vai depender do tamanho do dormitório. A explicação do porquê esse indicador era utilizado apenas para moradias de aluguel coloca que, nas próprias, isso poderia ser sanado com a construção de mais um quarto, ou com a venda do imóvel e a mudança para uma unidade maior.

Embora os conceitos envolvidos: segurança material, ventilação e privacidade sejam indiscutíveis, sua operacionalidade é complicada. Todo indicador operacional carrega uma grande dose de arbitrariedade, o que torna ainda mais complicada a utilização prática de um conceito. A Fundação João Pinheiro (FJP) lista ainda como indicadores de inadequação dos domicílios o adensamento excessivo de moradores em domicílios próprios (o indicador continua sendo três ou mais pessoas por dormitório), qualquer carência de serviços de infraestrutura (não dispor de ao menos um dos serviços básicos: iluminação elétrica, rede geral de canalização de água com canalização interna, rede geral de esgotamento sanitário ou fossa séptica e coleta de lixo), inadequação fundiária, cobertura inadequada, inexistência de unidade sanitária domiciliar exclusiva.

Percebe-se que os indicadores que definem moradia adequada no Brasil são restritos: em relação a saúde e bem-estar, colocam parâmetros mínimos - matérias de construção duráveis, existência de infraestrutura sanitária básica, adensamento máximo, sanitário exclusivo, adequação fundiária, relação aluguel/renda mínima, convivência familiar indesejada. Até na operacionalidade o conceito brasileiro é histórico e regional. São parâmetros mínimos, os possíveis para o país neste momento. Mas não os desejáveis em relação a um completo bem-estar domiciliar. Os desejáveis deveriam considerar todas as relações habitação-saúde e bem-estar.

\section{Relações habitação-saúde}

Como analisar essas relações? Uma forma possível seria através do agrupamento das necessidades habitacionais em quatro grandes grupos:

Casa e doenças transmissíveis: necessidades relacionadas com água, esgoto, sanitários, vetores, tanto na unidade como no entorno, conservação da comida, espaços nos dormitórios, ventilação e insolação

Já é bastante conhecida a relação entre o correto abastecimento de água e adequado destino dos dejetos com doenças entéricas. A mortalidade infantil no município de São Paulo, que atingia 89,7 óbitos para cada 1000 nascidos vivos 
em 1940, reduziu-se a 15,70 por 1000 em 2000, após esforço em aumentar os domicílios servidos por rede pública de água para 98,6\% e por rede de esgotamento sanitário para 87,8\%. Em 2010 esse coeficiente se reduz ainda mais, para 11,51 por 1000. Em 1968 apenas 52,4\% dos domicílios paulistanos eram servidos por abastecimento de água e $41,3 \%$, por rede de esgoto. As doenças infecciosas e parasitárias representavam, em 2003, menos que 7\% das causas de óbito na população com menos de cinco anos, no município. Já em 1920, doenças de veiculação hídrica (febre tifoide e paratifoide, cólera, disenteria, diarreias, gastroenterites e parasitas intestinais) chegaram a representar $27 \%$ do total dos óbitos infantis.

Em relação à densidade populacional, a relação já não aparece de forma clara. Aponta-se frequentemente o aumento da mortalidade infantil, que duplicaria em unidades com mais de duas pessoas por cômodo. Pesquisas americanas (Brasil, 1966) colocam o coeficiente de mortalidade infantil aumentando de $47 / 1000$ nascidos vivos em casas de cômodos amplos até 276/1000 em casas com poucas peças e pequenas Há, entretanto, pouca evidência para se concluir impactos diretos, segundo trabalho do Centre for Comparative Housing Research (2004). Segundo essa revisão, os efeitos do superadensamento são de difícil mensuração: muitos autores utilizam superfície por morador; outros, pessoas por cômodo ou por domićlio, o que fornece distintas medidas e interpretações. Além disso, problemas de causa e efeito podem ser mascarados. Uma pessoa pobre e com saúde debilitada poderá habitar uma casa superadensada por não ter condições de morar melhor. A casa, dessa forma, não será variável causal da falta de saúde, mas associada. Há efeitos diretos do superadensamento na educação, dado que sua presença mostra pouco espaço para estudo, além de possíveis efeitos na saúde mental e mesmo física, dado que facilita o contágio. Martin (apud Mitchell, 1971) comenta que diminuir densidade domiciliar visando diminuir as taxas de moléstias infecciosas é extremamente ineficaz, dado que há outras relações espúrias.

A rápida urbanização e o crescimento da mancha urbana impermeabilizaram o solo. E, nos países pobres, essa urbanização não foi acompanhada por uma adequada rede de infraestrutura. O que se vê nos últimos anos no Brasil é o avanço da infestação pelo mosquito Aedes aegypti, inseto extremamente bem equipado para habitar ambientes urbanos em países tropicais, com calor e umidade. Cidades impermeabilizadas, que acumulam poças de água, metrópoles com deficiência de infraestrutura, onde a coleta de lixo é insuficiente e o saneamento básico idem constituem hábitat ideal para o mosquito. Pressão na rede de abastecimento reduzida fez que a população estocasse água, nem sempre em recipientes fechados. Como afirmam Tauil $(2003 ; 2006)$ e Timerman (2016), uma mudança no modelo de urbanização se faz necessária. O controle dos vetores, tanto dentro da moradia como no bairro, é passo importante para uma habitação saudável. Pisos de terra abrigam pulgas, nematelmintos, baratas, escorpiões. Relato de Lanoix (apud OMS, 1961, p.42) descreve as favelas do 
Rio de Janeiro no século passado: "Na favela $40 \%$ da população adulta apresenta dilatação aórtica, pela necessidade de transportar água e cargas pelos abruptos caminhos das colinas. O índice de tuberculose é de 20\%; 95\% dos habitantes têm helmintíases". A troca de pisos de terra batida por pisos cimentados costuma ser fator de mudança decisiva na destruição de parasitas intestinais. Paredes de barro com gretas abrigam formigas e barbeiros. Segundo Tauil (2006), conseguiu-se a eliminação, em grande parte do território nacional, do principal vetor da doença de Chagas, o Triatoma Infestans. Ele abriga-se preferencialmente em casas de pau a pique, onde a borrifação com inseticida foi eficaz. E as casas urbanas, agora franca maioria, raramente utilizam esse material.

Infecções transmitidas pelo ar, devido a bactérias, richettsias e vírus são comuns no homem. As pequenas gotas que albergam os micro-organismos passam de pessoa a pessoa pelo ar, pelo contato direto ou por ingestão. O número de horas que um ser humano passa em seu domicílio é elevado (de 10 a 24 horas, quando se trata de recém-nascido). Assim, as más condições da casa, sobretudo quando acompanhadas de má nutrição e falta de higiene, predispõem às infecções respiratórias. Projetos de unidades que juntam mofo ou que não garantem ventilação causam diretamente problemas respiratórios. Em favelas e na periferia, em São Paulo, é comum observarem-se paredes úmidas devido à má impermeabilização da cobertura. O mofo, aliado à falta de ventilação, causa repetidas bronquites, sobretudo nas crianças, podendo originar infecções mais graves. Quando se pergunta o medicamento mais vendido, é comum a farmácia próxima citar Aerolin. Na África, no Sahel, demonstrou-se que em certos tipos tradicionais de casas indígenas, nos quais o volume de ar era só a metade do que nas casas ampliadas e ventiladas, havia o dobro do Streptococus Salivarius e Escheria Coli por unidade de volume, e o total de bactérias era quase dez vezes maior. A incidência de meningite cerebroespinhal era de cinco a dez vezes superior nas casas tradicionais, onde não há ventilação cruzada, do que nas casas modernas. Uma forma de reduzir a endemia de meningite A seria melhorar a ventilação das casas. Estudos realizados no Reino Unido demonstraram que a desinfecção do ar por raios ultravioleta pode reduzir incrivelmente a quantidade de bactérias transmissoras de infecções respiratórias nas escolas (Air Hygiene Commitee, 1954). Daí a importância de garantir a insolação, sobretudo em dormitórios.

Casa e necessidades fisiológicas: sobre conforto térmico e acústico, ar puro, luz e iluminação, local para exercício e brincadeiras, facilidade de manutenção.

Para que uma casa seja saudável é necessário que reúna as condições impostas pelas necessidades fisiológicas do homem (Goromosov, 1968), a saber: temperatura adequada, fornecendo um microclima agradável; ar interior puro e com condições adequadas de circulação, iluminação natural e artificial, bem-estar acústico e projeto adequado, de tal forma que os ocupantes possam rea- 
lizar seus afazeres sem fadiga excessiva, oportunidade de exercício e lazer ativo e passivo. Estudos franceses recomendam a temperatura interna do ar em torno de 24 graus, com umidade relativa de $60 \%$. Em regiões quentes e úmidas da antiga União Soviética recomendavam-se 24 a 25 graus, com umidade relativa do ar em 50\% a 60\%. E, em relação à construção em climas quentes, indica-se a plantação de árvores e arbustos, além de cultivo de plantas em balcões e janelas, a disposição de edifícios voltados para o sol nascente e com ventilação cruzada, uso de persianas e toldos, pintura de paredes em tom claro que refletem o calor. $\mathrm{O}$ uso combinado desses métodos pode permitir o rebaixamento, sem o uso de meios mecânicos, de 5 a 7 graus. Quanto à ventilação, uma série de estudos

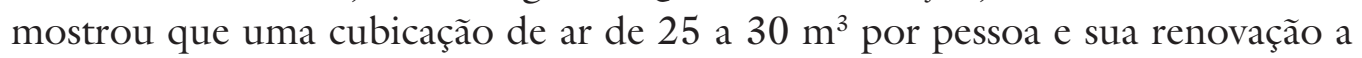
cada hora parece ser uma norma adequada (normas do Centre Scientifique et Technique du Bâtiment). Nota-se que nos cômodos onde há janela só de um lado o ar se renova 0,7 vez por hora. Já onde há janelas em lados opostos, a renovação sobe para 1,0 a 1,5 vez por hora.

As normas de exposição à luz solar variam de país para país: por exemplo, na antiga União Soviética todas as moradias deveriam usufruir ao menos três horas de luz solar direta e contínua no período que vai de 22 de março a 22 de setembro. Na Polônia, na França e nos Países Baixos o mínimo aceitável é de uma hora por dia entre 22 de fevereiro e 22 de outubro. Em São Paulo o Código de Obras prevê uma hora de insolação no dia mais curto do ano (solstício de inverno). Além do número de horas de exposição à luz solar, importante bactericida e fungicida, existem regulamentos e prescrições quanto ao tamanho das janelas, garantindo iluminação natural. Em São Paulo, todas as aberturas devem ser voltadas diretamente para espaços livres, com área correspondente a $1 / 7$ da área do piso. Há normas também para a iluminação artificial: as normas americanas fixam uma intensidade de iluminação que vai de 300 a 2000 lux. $\mathrm{Na}$ Alemanha, em locais de trabalho, chaga-se a recomendar 4000-8000 lux.

Uma das principais funções da moradia moderna é propiciar condições para o descanso. O ruído prejudica o repouso, relaxamento, leitura e sono. Segundo alguns autores, o ruído não apenas perturba, como pode influir na aparição de transtornos cardiovasculares e psíquicos. Em São Paulo, nas chamadas $\mathrm{Zl}$ os limites permitidos são 55 decibéis durante o dia e 45 à noite. Em termos de comparação, a conversação de duas ou três pessoas atinge $73 \mathrm{db}$; o som de um piano, $86 \mathrm{db}$; a música de rádio, $85 \mathrm{db}$. Recomenda-se que a casa deva ter a possibilidade de, com portas e janelas fechadas, isolar 50 decibéis. Ruídos de baixa frequência não têm se mostrado danosos para a saúde (Karodina apud Goromosov, 1968).

A poluição do ar é gerada sobretudo fora do domicílio, por veículos automotores e indústrias. Mas nele penetra impunemente. Estudos têm mostrado

que quando se soma o efeito dos poluentes ao frio, os habitantes poderão ficar vulneráveis durante quase uma semana, ou seja, determinada semana em São 
Paulo poderá ser letal. Mostrou-se também que os poluentes e as variáveis meteorológicas explicam em média $70 \%$ da variância captada nas internações por doenças respiratórias. (Nobre et al., 2010, p.28)

A associação entre dióxido de enxofre e monóxido de carbono com frio e umidade eleva as doenças respiratórias do trato superior, enquanto a associação dessa característica climática com ozônio e material particulado eleva as do trato inferior, como asma e bronquites. A unidade domiciliar pode proteger um pouco o morador, mas a poluição do ar nela entra também.

Casa e acidentes domésticos, versando sobre segurança material, proteção contra fogo e inundações, proteção contra choques, queimaduras, quedas, envenenamento de gás, proteção contra automóveis.

A Organização Mundial da Saúde (1961), já na década de 1960, comentava que a mortalidade por acidentes domésticos no Canadá e nos Estados Unidos foi duas vezes maior que a por tuberculose na década de 1950. No Brasil, a bibliografia sobre a morbidade e a mortalidade por acidentes domésticos é rara. Dados não publicados da Profa. Dra. Maria Helena Silveira, da Faculdade de Saúde Pública da USP, indicavam que, em 1980, 63,6\% das quedas ocorriam no domicílio. O Portal Brasil (4 de setembro de 2013) computa 11,6 mil internações por acidentes em crianças em 2010, com 253 mortes de crianças até 1 ano. Wilson (1966) estudou especificamente o distrito de Vila Madalena em 1965: entre 2.471 moradores das 498 casas pesquisadas, 687 (27,4\%) haviam sofrido algum acidente em casa no ano anterior, em geral com pequena gravidade. Quase 47\% não tiveram nenhuma limitação física; $52 \%$ ficaram incapacitados por um dia; 0,7\% sofreram deformidade permanente; e 0,3\%, a morte. Quanto à natureza do acidente, as quedas predominavam, tanto em quantidade como em gravidade. Queimaduras, envenenamentos, afogamentos, choques são também citados. São evitáveis, se os projetistas e construtores tomarem alguns cuidados básicos, como a existência de corrimão nas escadas, o uso de pisos antiderrapantes, a segurança em piscinas, o cuidado com sacadas e janelas, os projetos de cozinha e lavanderia, o desenho industrial mais adequado em fogões e panelas, a iluminação adequada. É bastante conhecido o acidente com tanques, comum na periferia paulistana: era usual colocar o tanque simplesmente apoiado em duas muretas. A criança se apoiava na borda, e o recipiente caia, afundando seu tórax. Isso foi evitado apenas parafusando o tanque nos apoios. A Lei Moura, que trata da legalização dos cortiços no município de São Paulo, enunciando seus requesitos mínimos, colocou como requisito básico a retirada do bujão de gás do cômodo, cuidado essencial para se evitar vazamentos tóxicos e explosões. Nos Estados Unidos estimou-se que em 196820 milhões de pessoas ficaram feridas em acidentes domésticos (na época, cinco vezes maios que em acidentes de automóvel) e, entre esses feridos, 110.000 tornaram-se inválidos. E taxa de mortalidade por acidentes domésticos foi estimada em 142/100.000 para este local e data. 
Casa e saúde mental, com necessidades que envolvem privacidade, vida familiar, vida comunitária, facilidade de manutenção e de execução das atividades domésticas, satisfação estética e concordância com os padrões locais.

A relação entre casa e saúde mental é ainda inconclusiva, dada as dificuldades de definição e as variáveis intervenientes. Reconhece-se que um layout adequado não possa curar doenças mentais já existentes, mas pode prevenir seu futuro desenvolvimento, no sentido que o layout físico pode atuar como agente de reforço em traços de personalidade já estruturados. Mas é extremamente complicado isolar os conjuntos de fatores sociais existentes na moradia do homem, que vão muito além do espaço físico. Chapin (1951) coloca que pelo menos dois fatores do layout físico podem ser estudados separadamente: a privacidade $\mathrm{e}$ a circulação. Segundo ele, a falta de privacidade traduz-se facilmente em sequelas mentais. O isolamento é necessário para ler, estudar, gozo estético e erótico. Alguns autores citam evidências de desenvolvimento de traços esquizofrênicos em cortiços. Novamente, torna-se difícil relacionar causalidade: o habitar em cortiços pode ser consequência, e não causa. Pessoas com dificuldades mentais e sociais tendem a usufruir menos renda, portanto ter acesso prejudicado à moradia de boa qualidade. Estudos da equipe de Chombart de Lauwe (1967) comentam a importância do estudo da superpopulação e confinamento, indicando alguns limites que seriam indispensáveis. Assim, o limite patológico, abaixo do qual ocorreriam perturbações na saúde física e mental, de 8 a $10 \mathrm{~m}^{2}$ por pessoa e 2,5 habitantes por cômodo, o limite crítico, quando a probabilidade disso acontecer estaria grandemente aumentada, de 12 a $14 \mathrm{~m}^{2}$ por pessoa e 2 pessoas por cômodo. Esses limites foram delimitados estudando-se o comportamento entre pais e filhos (fadiga materna, castigos infringidos às crianças, violência e nervosismo), entre famílias pesquisadas na França. Os limiares de superfície por pessoas e pessoas por cômodo variam bastante entre países. No Canadá, a unidade superpovoada é simplesmente aquela em que o número de pessoas supera o de cômodos. Na Bélgica a superfície por pessoa ideal, normatizada pela Societé Nationale du Logement, varia conforme a unidade seja casa ou apartamento e pelo número de moradores: para 2 residentes o mínimo seria de $21 \mathrm{~m}^{2}$ por pessoa para casas e $15 \mathrm{~m}^{2}$ por pessoa por apartamento. Tanto a Organização Mundial de Saúde (OMS) como a American Public Health Association (APHA) encorajam pesquisas sobre as implicações da densidade domiciliar elevada na saúde e muitos autores têm se debruçado sobre o assunto, ainda inconclusivo (Evans et al., 2001; 2003; Gabe; William, 1986; Wells, 2000, entre outros). Pesquisadores têm notado uma associação, entre moradores de rua e embaixo de viadutos, de certa organização espacial no interior do domicílio e famílias mais estruturadas. Assim, embaixo do viaduto do Tatuapé, por exemplo, barracos com algum tipo de organização interna mostravam famílias com crianças na escola, presença da mãe e às vezes do pai, enquanto abrigos totalmente desordenados indicavam mãe ausente, crianças abandonadas e sem escola (Rabinovich, 1992; Taschner; Rabinovich, 1998). 


\section{Meio ambiente, habitação e saúde no município de São Paulo}

O município de São Paulo, até o início do milênio, apresentava um padrão de crescimento nitidamente periférico, com a população pobre se alojando nas franjas periféricas e, não raro, ultrapassando as fronteiras da capital e indo residir nos municípios limítrofes. Entre 1980 e 1991 os três anéis centrais ${ }^{1}$ (Taschner, 1990; Taschner; Bogus, 1998) já apresentavam perda de 253 mil moradores, perda essa que cresceu para 265 mil entre 1991 e 2000. Na primeira década do século XX essa tendência se inverte, com ganho de 216 mil residentes nos anéis central, interior e intermediário. $\mathrm{O}$ anel periférico ainda cresce, mas com incremento menos vigoroso (sua taxa geométrica de crescimento populacional, da ordem de 4,7\% ao ano entre 1960 e 1970 e 3,66\% ao ano entre 1970 e 1980 , reduziu-se para $0,76 \%$ anuais entre 2000 e 2010 , versus taxas de $1,24 \%$ e $1,05 \%$ nos anéis central e interior, para o mesmo período). Alguns reflexos começam a aparecer, com a diminuição dos imóveis vagos, de um lado, e mudanças no padrão de mortalidade, de outro.

A cidade apresenta condições bastante boas de infraestrutura básica: $99,09 \%$ dos domicílios são servidos por rede de água; $91,90 \%$ estão ligados à rede de esgoto; e $95,09 \%$ têm o lixo coletado por serviços de limpeza (dados de 2010). Mas há grande número de famílias residindo em assentamentos precários, em áreas de grande vulnerabilidade. Excluídas do mercado de moradias privadas e não atendidas por políticas públicas, essas famílias vão ocupar favelas, cortiços, loteamentos irregulares, construindo seus domić́lios num processo lento de autoconstrução, de acordo com o seu fluxo de recursos, e frequentemente residindo em casas pouco saudáveis. As taxas de crescimento da população favelada têm sido, historicamente, maiores que a da população municipal como um todo: entre 1980 e 1991 foi de $7,07 \%$ anuais, enquanto a da população municipal foi de $1,13 \%$ ao ano; entre 1991 e 2000 a população favelada cresceu à taxa de $2,82 \%$ ao ano, enquanto a taxa da cidade como um todo foi $0,92 \%$. E entre 2000 e 2010 , as taxas foram de $3,22 \%$ e $0,76 \%$, respectivamente. $\mathrm{E}$ o crescimento das favelas é maior nos anéis exterior e periférico.

O padrão de mortalidade geral é distinto por anel. Para um total de 70.817 óbitos no município de São Paulo em 2012, nota-se que a proporção de óbitos por doenças infecciosas e parasitárias é maior no anel periférico, assim como a dos óbitos por causas externas (homicídios, suicídios, acidentes). A Tabela 1 detalha algumas causas de morte.

Os distritos com maior proporção de óbitos por causas externas são Jardim Ângela (17,52\%), Grajaú (16,26\%), Jardim São Luís (16,23\%), Marsilac $(16,00 \%)$, Parelheiros (14,50\%), Anhanguera (14,35\%) e Iguatemi (13,67\%). Localizam-se todos na periferia. Alguns distritos centrais (pertencentes aos anéis central e interior) mostram proporção de óbitos por causas externas maior que a média municipal $(8,84 \%)$ : são Brás (11,86\%), Pari $(0,27 \%)$ e Sé $(10,27 \%)$. São distritos com percentual grande de população pobre e grande número de corti- 
ços. Condições de moradia superadensadas não causam óbitos, mas contribuem para desavenças e brigas, facilitam o aparecimento de acidentes e de contágio. Tanto na periferia como nos cortiços centrais, a pobreza se associa a má moradia, mesmo que ela seja infraestruturada. Nota-se também, pela Tabela 1, que o padrão de mortalidade por doenças infecciosas e parasitárias também varia por anel, sendo mais alto nos anéis central e periférico. Para o município como um todo, a proporção de óbitos por essas causas é de 3,90\%. Mas em alguns distritos periféricos, essa porcentagem é ultrapassada: Anhanguera $(8,26 \%), \mathrm{Ci}$ dade Tiradentes $(6,70 \%)$, Itaim Paulista (5,94\%), Jardim Ângela $(5,57 \%)$, Vila Jacuí $(5,46 \%)$. Nesses casos, a associação entre falta de infraestrutura sanitária é imediata. Mas percebe-se que em alguns distritos centrais a proporção de óbitos por infecciosas e parasitárias também é mais alta que a média municipal: Pari $(5,92 \%)$, Brás $(5,55 \%)$, República $(5,20 \%)$, Bom Retiro (4,29\%), Santa Cecília $(4,12 \%)$. Para esses locais, a associação pode ser feita com moradia precária e adensada.

Tabela 1 - Município de São Paulo. Proporção de óbitos por algumas causas no total de óbitos, 2012, por anel

\begin{tabular}{|c|c|c|c|c|c|c|}
\hline \multirow{2}{*}{$\begin{array}{l}\text { Algumas causas } \\
\text { de óbito }\end{array}$} & \multicolumn{6}{|c|}{ Anéis } \\
\hline & Central & Interior & $\begin{array}{l}\text { Inter- } \\
\text { mediário }\end{array}$ & Exterior & Periférico & Total \\
\hline $\begin{array}{l}\text { Algumas doenças } \\
\text { infecciosas e parasitárias }\end{array}$ & $3,86 \%$ & $3,22 \%$ & $3,23 \%$ & $3,63 \%$ & $4,44 \%$ & $3,90 \%$ \\
\hline Causas externas & $6,32 \%$ & $5,25 \%$ & $5,15 \%$ & $7,54 \%$ & $11,23 \%$ & $8,84 \%$ \\
\hline $\begin{array}{l}\text { Doenças do aparelho } \\
\text { respiratório }\end{array}$ & $12,88 \%$ & $14,25 \%$ & $14,18 \%$ & $12,46 \%$ & $11,77 \%$ & $21,61 \%$ \\
\hline $\begin{array}{l}\text { Doenças do aparelho } \\
\text { circulatório }\end{array}$ & $30,98 \%$ & $29,79 \%$ & $31,33 \%$ & $31,62 \%$ & $30,91 \%$ & $30,96 \%$ \\
\hline Neoplasias & $22,63 \%$ & $23,49 \%$ & $22,46 \%$ & $20,99 \%$ & $17,85 \%$ & $19,99 \%$ \\
\hline $\begin{array}{l}\text { Doenças do aparelho } \\
\text { digestivo }\end{array}$ & $6,44 \%$ & $5,27 \%$ & $5,27 \%$ & $5,72 \%$ & $6,00 \%$ & $5,76 \%$ \\
\hline $\begin{array}{l}\text { Doenças do aparelho } \\
\text { geniturinário }\end{array}$ & $2,89 \%$ & $3,70 \%$ & $3,42 \%$ & $2,95 \%$ & $2,53 \%$ & $2,88 \%$ \\
\hline $\begin{array}{l}\text { Doenças do sistema } \\
\text { nervoso }\end{array}$ & $4,92 \%$ & $4,98 \%$ & $4,52 \%$ & $3,74 \%$ & $2,55 \%$ & $3,48 \%$ \\
\hline Total & $100,00 \%$ & $100,00 \%$ & $100,00 \%$ & $100,00 \%$ & $100,00 \%$ & $100,00 \%$ \\
\hline
\end{tabular}

Fonte: Fundação Seade.

Percebem-se dois espaços vulneráveis no município: o anel central (ou pelo menos alguns dos seus distritos) e o anel periférico. Na análise da mor- 
talidade infantil apenas a periferia aparece como vulnerável (Tabela 2). O anel interior tem seu resultado alterado pelos dados do Brás, em que o coeficiente de mortalidade infantil alcançou 23,11 óbitos para cada 1000 nascidos vivos, e a proporção de mortes de menores de 1 ano foi de $7,73 \%$. Mas nos anéis central e interior os únicos distritos com mortalidade infantil maior que a média municipal foram Brás, Belém e Barra Funda. Deve ser colocado que a mortalidade infantil diminuiu no município, passando de 14,1 óbitos por 1000 nascidos vivos em 2014 para 11,32 no ano 2012. Mas o diferencial por distrito continuou alto: no distrito de Vila Sonia o coeficiente foi de 4,26 óbitos por 1000, enquanto no Brás chegou a 23,11, em Cachoeirinha a 17,45, e em Cidade Tiradentes a 17,42 por 1000 nascidos vivos.

Tabela 2 - Município de São Paulo. Mortalidade infantil e proporção de óbitos de menores de 1 ano no total de óbitos, por anel, 2012

\begin{tabular}{l|c|c}
\hline Anel & CMI Óbitos menores 1 ano/1000 NV & \% óbitos menores de 1 ano \\
\hline Anel central & 5,85 & 1,05 \\
\hline Anel interior & 10,46 & 1,70 \\
\hline Anel intermediário & 8,38 & 1,47 \\
\hline Anel exterior & 10,93 & 2,39 \\
\hline Anel periférico & 12,50 & 4,10 \\
\hline MSP & $\mathbf{1 1 , 3 2}$ & $\mathbf{2 , 8 1}$ \\
\hline
\end{tabular}

Fonte: Fundação Seade.

A urbanização tem se mostrado inevitável, embora a cidade de São Paulo apresente taxa declinante. E, como se observou, a infraestrutura básica espalhou-se por todo o tecido urbano, mesmo nas favelas: no ano $2010,97,8 \%$ das casas faveladas tinham água de rede pública e $95 \%$, água encanada no domicílio; $67,4 \%$ eram servidas por rede pública de esgoto, $99,9 \%$ tinham energia elétrica e $98,9 \%$, algum serviço de coleta de lixo. Esses dados se refletem na forte queda da mortalidade infantil, de 30,90 em 1991 para 11,32 óbitos por 1000 nascidos vivos em 2012, duas décadas depois.

A situação das favelas paulistanas, entretanto, continua bastante precária. A área ocupada pelos assentamentos subnormais em 2010 era de 4.404,63 hectares, ou seja, menos de 3\% da superfície municipal total. Essa área, entretanto, é ocupada por $11,38 \%$ do volume populacional. Isso vai resultar em densidades altas: as favelas do anel interior mostram densidade de 913 habitantes por hectare, semelhante a uma Copacabana altamente verticalizada. No anel periférico a densidade demográfica é menor, de 254 habitantes por hectare, e a verticalização menos intensa, com $63 \%$ das unidades de moradia com dois andares e 3,7\% com três ou mais andares.

Essa densidade alta se traduz em pouco espaçamento entre unidades, prejudicando ventilação e insolação, além do comprometer a privacidade e o iso- 
lamento acústico. A falta de espaçamento foi retratada na Leitura Territorial, feita pelo Censo Demográfico de 2010: no município de São Paulo em 84\% dos domicílios favelados não há espaçamento entre as unidades domiciliares, mostrando um tecido urbano pouco adequado à implantação de redes de infraestrutura urbana. "Cerca de 90 mil unidades domiciliares situam-se em encostas com declive acentuado, sobretudo nos anéis exterior e periférico. E a verticalização das casas nas favelas do município é grande; $70 \%$ das moradias têm mais de 1 pavimento" (Pasternak; D’Ottaviano, 2016). Entre as 355.756 unidades faveladas no município em 2010, 24,70\% alocavam-se às margens de cursos de água, quase $2 \%$ são palafitas e $2,5 \%$ estão em unidades de conservação. Isso soma cerca de 100 mil domicílios, com população estimada de mais de 377 mil pessoas sujeitas a riscos de alagamento ou solapamento. Soma-se a esse número de domicílios e pessoas em risco as mais de 4.300 unidades domiciliares sob fios de alta tensão, as quase 6 mil em faixas de domínio de ferrovias e rodovias e as 1.176 alocadas sobre aterros sanitários. O rótulo de casa adequada e saudável decididamente não se associa a esse universo. Se a política de urbanização de favelas conseguiu êxito ao fornecer água a quase todos os domićlios nos assentamentos subnormais, esgoto a mais de $67 \%$ deles e coleta de lixo (embora com frequência desconhecida e com o auxílio de containers), as casas faveladas continuam apresentando fortes precariedades: embora majoritariamente em alvenaria e com sanitário individual, são mal ventiladas, sem exposição à luz solar, úmidas, mal divididas, com cobertura pouco isolante e que permite a infiltração de água, possibilitando o aparecimento de mofo. $\mathrm{O}$ espaço comunitário não é tratado, apresentando não raro montes de lixo e entulho, atraindo artrópodes, mosquitos e ratos. Não há área verde nem outro tipo de área de lazer, o arruamento é tortuoso e pouco claro. $\mathrm{O}$ desafio de tornar esse espaço e essas unidades de moradia casas saudáveis torna-se cada vez mais complexo, o que traz uma reflexão sobre as políticas de urbanização de favelas atuais.

Nota

1 A divisão do tecido urbano em cinco anéis seguiu metodologia proposta por Pasternak Taschner em trabalho para a Empresa Municipal de Urbanização (São Paulo, 1977), posteriormente reutilizada em publicação de 1999. A construção dos anéis deu-se privilegiando a variável demográfica proporção de população jovem sobre a população total em 1970. Esse critério demográfico mostrou-se competente também para uma divisão socioeconômica, aproximando-se da clássica espacialização que dividia o tecido urbano em centro histórico, centro expandido e periferia. Os 58 distritos de 1970 e 1980 foram compatibilizados com a nova divisão em 96 distritos, que perdura até hoje. Os cinco anéis apresentam os seguintes distritos componentes:

Anel central (6): Bela Vista, Consolação, Liberdade, República, Santa Cecília e Sé.

Anel interior (11): Barra Funda, Belém, Bom Retiro, Brás, Cambuci, Jardim Paulista, Mooca, Pari, Perdizes, Pinheiros e Vila Mariana 
Anel intermediário (15): Água Rasa, Alto de Pinheiros, Campo Belo, Carrão, Cursino, Moema, Ipiranga, Itaim Bibi, Lapa, Penha, Sacomã, Saúde, Tatuapé, Vila Guilherme e Vila Leopoldina

Anel exterior (28): Aricanduva, Butantã, Cachoeirinha, Cangaíba, Casa Verde, Cidade Ademar, Freguesia do Ó, Jabaquara, Jaçanã, Jaguara, Jaguaré, Limão, Mandaqui, Morumbi, Pirituba, Rio Pequeno, Santana, São Lucas, Sapopemba, Tremembé, Tucuruvi, Vila Formosa, Vila Maria, Vila Matilde, Vila Medeiros, Vila Prudente, Vila Sonia e São Domingos

Anel periférico (36): Anhanguera, Artur Alvim, Brasilândia, Campo Grande, Campo Limpo, Capão Redondo, Cidade Dutra, Cidade Líder, Cidade Tiradentes, Ermelino Matarazzo, Grajaú, Guaianazes, Iguatemi, Itaim Paulista, Itaquera, Jaraguá, Jardim Ângela, Jardim Helena, Jardim São Luis, José Bonifácio, Marsillac, Parelheiros, Parque do Carmo, Pedreira, Perus, Ponte Rasa, Raposo Tavares, Santo Amaro, São Mateus, São Miguel, São Rafael, Socorro, Vila Andrade, Vila Curuçá, Vila Jacuí e Lajeado

\section{Referências}

AIR HYGIENE COMMITTEE. Air disinfection with ultra - violet irradiation: its effects on illness among school children. London, Medial Research Council. Special Report, n.295, 1954.

AMERICAN PUBLIC HEALTH ASSOCIATION. Committee on the hygiene of housing. Basic principles of healthful housing, 1945.

BRASIL. Ministério do Planejamento e Coordenação Econômica. Desenvolvimento social: habitação. Rio de Janeiro, 1966 (versão preliminar).

CENTRE FOR COMPARATIVE RESEARCH The impacts of overcrowding in Health and Education. A review of evidence and literature. London: Office of the Deputy Prime Minister, May 2004.

CHAPIN, F. S. Some housing factors related to mental hygiene. American Journal of Public Health, New York, v.41, p.839-945, 1951.

CHOMBART DE LAUWE, P. H. et al. Famille et habitation. Paris: Centre National de la Recherche Scientifique (CNRS), 1967.2v.

COHEN, S. et al. Habitação saudável e ambiente favorável à saúde como estratégia de promoção da saúde Ciência e Saúde Coletiva, Rio de Janeiro, v.12, n.11, p.191-8, 2007.

EVANS, G. W.; SALTZMAM, H.; COPERMAN, J. Housing quality and children's social-emotional health. Environment and Behavior, v.33, n.1, p.389-99, 2001.

EVANS, G. W.; WELLS, N. M.; MACH, A. Housing and mental health: of a review of the evidence and a methodological and conceptual critique. Journal of Social Issues, v.59, n.3, p.475-500, 2003.

FUNDAÇÃO JOÃO PINHEIRO. Centro de Estatística e Informação. Déficit habitacional no Brasil. Belo Horizonte, 2008.

GABE, J. WILLIAM, P. Is space bad for your health? - the relationship between crowding in the home and emotional distress in women. Sociology of Health and Illness, v.8, p.351-71, 1986. 
GOROMOSOV. M. S.The physiological basis of health stadndars for dwellings. Gengra, Weold Healtu Organization. Public Health Papers, n.33, 1968.

HAVEL, J. E. Habitat et logement. Paris: Presses Universitaires de France (PUF), 1968.

HERMETO, M. P. Habitação saudável: ampliando a atenção à saúde. Cadernos de Arquitetura e Urbanismo, Belo Horizonte, v.16, n.8, p.47-158, 2009.

MITCHELL, R. E. Some social implications of high density housing. American Sociological Review, v.39, p.18-29, fev. 1971.

NOBRE. C. A. et al. RMSP e as vulnerabilidades às mudanças climáticas. INPE/Unicamp/USP/IPT/Unesp. São Paulo, Programa FAPESP de pesquisa em mudanças climáticas globais. São Paulo, 2010.

ORGANIZAÇÃO MUNDIAL DA SAÚdE. Documentos Básicos. Informe Técnico 225, 1961.

PASTERNAK, S.; D’OTTAVIANO, M. C. Favelas no Brasil e em São Paulo: avanços nas análises a partir da Leitura Territorial do Censo de 2010. Cadernos Metrópole, São Paulo, v.35, 2016 (no prelo).

RABINOVICH, E. P. A casa dos sem casa. Psicologia: Ciência e Profissão, São Paulo, v.2, n.3 e 4, p.16-23, 1992.

REDE BRASILEIRA DE HABITAÇÃO SAUDÁVEL. Disponível em: <http://www. cepis.ops-oms.org/index.html>. Acesso em: 5 fev. 2016.

SÃO PAULO. Município. Empresa Municipal de Urbanização. Departamento de Estudos Urbanos. Análise demográfica do Município de São Paulo. São Paulo: Emurb, julho de 1977 (Mimeo.).

TASCHNER, S. P. Habitação e demografia intra-urbana. Revista Brasileira de Estudos de População, v.7, p.3-34, 1991.

TASCHNER, S. P.; BOGUS, L. M. M. A cidade dos anéis. Cadernos de Pesquisa do LAP28, São Paulo, nov.-dez. 1998.

TASCHNER, S. P.; RABINOVICH, E. P. Modos de morar na rua. Cadernos de Pesquisa do LAP, São Paulo, jul.-ago. 1998.

TAUIL, P. L. Urbanização e ecologia da dengue. Cadernos de Saúde Pública. Rio de Janeiro, v.17, suplemento, p.89-102, 2003.

Perspectiva de controle de doenças transmissíveis por vetores no Brasil. Revista da Sociedade Brasileira de Medicina Tropical, v.39, n.3, p.257-77, maio/jun. 2006.

TIMERMAN, A. Rápida urbanização deu condições para o avança do "Aedes". Estado de S. Paulo. São Paulo. 3.2.26 2016, Metrópoles, Al3.

WELLS, N. M. Housing quality \& women's mental health, a three wave longitudinal study. ENHR Conference, 2000.

WESTPHAL, M. F. O movimento cidades/municípios saudáveis: um compromisso com a qualidade de vida. Ciência e Saúde Coletiva, Rio de Janeiro, v.5, n.1, p.39-51, jan.-mar. 2000.

WILSON, D. Contribuição para o conbecimento da medicina preventiva dos acidentes domésticos. Estudo epidemiológico de um subdistrito de São Paulo. 1966. Tese apresentada para o provimento de cargo de professor catedrático de higiene e medicina preventiva. Faculdade de Medicina, Universidade de São Paulo. São Paulo, 1966. 
WORLD HEALTH ORGANIZATION. Housing-implications for health. Report of WHO Consultation. Genebra, 1987, 70p.

2010.

International workshop on Housing. Health and Climate Change. Genebra,

RESUMO - O artigo discute o conceito de moradia adequada, constatando que os indicadores utilizados no Brasil, embora adequados para o momento e o local, não cobrem todas as condições habitacionais para promover a saúde e o bem-estar dos moradores. Explicita a relação habitação-saúde através da análise de quatro dimensões: casa e doenças transmissíveis, casa e necessidades fisiológicas, casa e acidentes domésticos, casa e saúde mental. Utilizando informações do Censo de 2010 e estatísticas vitais de 2012, analisa as condições urbanas e domiciliares do município de São Paulo, observando que o padrão da mortalidade infantil e geral varia espacialmente. Finaliza o artigo com a descrição das condições ambientais das favelas paulistanas.

PALAVRAS-CHAVE: Habitação saudável, Moradia e saúde, Déficit habitacional, Habitação em São Paulo.

ABSTRACT - This paper discusses the concept of proper housing, showing that the indicators used in Brazil, although adequate for the time and place, do not cover all building conditions that promote health and well-being. It examines the relationship between health and housing by analyzing four dimensions: housing and transmissible diseases, housing and physiological needs, housing and domestic accidents, and housing and mental health. Using data from the 2010 Demographic Census and vital statistics for 2012, the article analyzes the environmental and urban conditions of the city of São Paulo, showing that infant and general mortality patterns vary spatially. The paper ends with a description of the environmental conditions of São Paulo's favelas (shantytowns).

KEYWORDS: Healthy housing, Housing and health, Housing deficit, Housing in São Paulo.

Suzana Pasternak é professora titular aposentada da Faculdade de Arquitetura e Urbanismo da Universidade de São Paulo. É arquiteta sanitarista pela Faculdade de Saúde Pública da USP, onde fez mestrado e doutorado. Foi coordenadora da área de Ciências Sociais Aplicadas do CNPq e vice-coordenadora nacional do Observatório das Metrópoles. @-suzanapasternak@gmail.com

Recebido em 13.2.2016 e aceito em 25.2.2016.

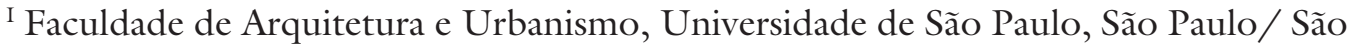
Paulo, Brasil. 